\title{
STUDI TINGKAT KERUSAKAN PERMUKAAN JALAN DENGAN KOMBINASI NILAI SURFACE DISTRESS INDEX DAN INTERNATIONAL ROUGHNESS INDEX
}

\author{
Pebrinar Riani Sangle ${ }^{1}$, Suryanti R. Tonapa ${ }^{2}$, Charles Kamba ${ }^{3}$ \\ 1,2,3Program Studi Teknik Sipil, Universitas Kristen Indonesia Paulus, \\ Jl. Perintis Kemerdekaan KM 13 Daya, Makassar \\ Email : pebrinar_sangle@ukipaulus.ac.id
}

\begin{abstract}
There are many national roads in Maluku, there that connect one area to another one of which is the Mako-Modanmohe road section on the island of Buru. This road is often traversed by vehicles with heavy loads, this causes damage. Research on the assessment of the level of road damage needs to be done to address the frequent damage. This study aims were to evaluate road pavement conditions functionally and compare the value of road conditions based on the International Roughnes Index (IRI) and Surface Distress Index (SDI) methods. Visual assessment of pavement conditions was obtained by conducting a field survey using the SDI method, the IRI value was secondary data obtained from the local government. The results of this study where the assessment of the level of road surface damage with a combination of SDI and IRI data were $23.81 \%$ good condition, $71.43 \%$ moderate condition, $4.76 \%$ lightly damaged and $0 \%$ beavily damaged. From the results of the assessment of the level of damage, the types of road bandling were $95.24 \%$ routine, $4.76 \%$ rehabilitation, $0 \%$ reconstruction
\end{abstract}

Keywords : IRI, Road Bandling Type, Road Functional Condition, SDI

\begin{abstract}
Abstrak
Di Provinsi Maluku terdapat beberapa ruas jalan Nasional yang menjadi penghubung antar kabupaten yang ada di Pulau Buru salah satunya adalah Ruas jalan Mako-Modanmohe. Jalan ini sering dilalui kendaraan dengan beban yang berat hal ini menyebabkan terjadinya kerusakan. Penelitian mengenai penilaian tingkat kerusakan jalan perlu dilakuan untuk mengatasi kerusakan yang sering terjadi. Tujuan dari penelitian ini adalah untuk mengevaluasi kondisi permukaan jalan secara fungsional dan membandingkan nilai kondisi jalan berdasarkan metode International Roughnes Index (IRI) dan Surface Distress Index (SDI). Metode SDI digunakan untuk penilaian kondisi perkerasan jalan yang dilakukan secara visual di lapangan. Untuk data IRI diperoleh dari Pejabat Pembuat Komitmen Wilayah 1.2 Pulau Buru. Hasil dari penelitian ini dimana penilaian tingkat kerusakan permukaan jalan dengan kombinasi SDI dan data IRI adalah 23,81\% kondisi baik, 71,43\% kondisi sedang, 4,76\% rusak ringan dan $0 \%$ rusak berat. Dari hasil penilaian tingkat kerusakan maka tipe penanganan jalan adalah 95,24\% rutin; 4,76\% rehabilitasi; $0 \%$ rekonstruksi.
\end{abstract}

Kata Kunci : IRI, Kondisi Fungsional Jalan, SDI, Tipe Penanganan

\section{PENDAHULUAN}

Jaringan jalan merupakan urat nadi perekonomian nasional sehingga jalan menjadi sarana transportasi yang sangat penting dalam memajukan perekonomian dan kesejahteraan masyarakat (Sukirman, 2007) (Bunga, 2019) (Kamba, 2018). Untuk kelancaran dalam system jaringan jalan dibutuhkan prasarana jalan yang baik.

Prasarana jalan nasional sangat penting dalam transportasi nasional, sekitar 95\% angkutan penumpang dan 92\% angkutan barang di Indonesia menggunakan jalan. Hal ini menyebabkan pengelolaan jalan merupakan aspek yang sangat strategis dan setiap keputusan dalam pengelolaan jalan harus didasarkan pada data yang akurat. Data merupakan basis utama dalam menentukan suatu kebijakan, dalam menentukan kebijakan penanganan jalan diperlukan suatu basis data kondisi jalan. Jenis basis data kondisi jalan bergantung pada maksud kebijakan yang akan ditentukan. Tingkatan akurasi dari data yang dikumpulkan bervariasi tergantung pada tingkat hierarki keputusan yang akan dibuat dan sistem yang dipakai untuk membuat keputusan dalam konteks penanganan jalan.

Dalam pelaksanaan Survei Kondisi Jalan, saat ini telah terdapat beberapa metode serta alat yang digunakan dalam melakukan Survei Kondisi Jalan (Road Condition Survey) dimana salah satu yang digunakan di Indonesia adalah survey secara visual. Data yang diperoleh dari alat digunakan untuk perhitungan nilai International Roughness Index (IRI) dan Surface Distress Index (SDI) yang merupakan ukuran kondisi fungsional permukaan jalan yang bersumber pada metode Bina Marga. Nilai IRI diperoleh langsung dari alat sedangkan nilai SDI diperoleh dari hasil perhitungan dari data survey lapangan. 
Surface Distress Index (SDI) adalah rasio kapasitas jalan yang diperoleh dari hasil pengamatan langsung dilapangan terhadap kerusakan jalan yang terjadi. Ada beberapa unsur yang digunakan untuk penentuan nilai indeks SDI yaitu $\%$ total luas retak jalan, lebar retak jalan rata-rata, jumlah kerusakan lubang per $100 \mathrm{~m}$, serta kerusakan akibat bekas roda/ rutting (kedalaman).

Berbagai penelitian yang pernah dilakukan tentang studi kerusakan jalan antara lain Penggunaan Metode International Roughness Index (IRI), Surface Distress Index (SDI) dan Pavement Condition Index (PCI) untuk Penilaian Kondisi Jalan di Kabupaten Wonogiri (Tho'atin). Evaluasi Tingkat Kerusakan Jalan Sebagai Dasar Penanganan Jalan (Studi Kasus Pada Ruas Jalan Sp Taniwel - Boeria) (Futwenbun, 2017). Tinjauan Kondisi Perkerasan Jalan dengan Kombinasi Nilai International Roughness Index (IRI) dan Surface Distress Index (SDI) pada Jalan Takengon - Blangkejeren (Baihaqi: Salaeh, 2018). Analisis Kerusakan Jalan Metode SDI Taluk Kuantan - Batas Provinsi Sumatera Barat. Evaluasi Kemantapan Permukaan Jalan Berdasarkan International Roughness Index Pada 14 Ruas Jalan di Kota Yogyakarta (Pembuain.A: Priyanto, 2018).

Tujuan penelitian ini adalah melakukan survei kondisi jalan untuk mengetahui tingkat kerusakan jalan serta tipe penanganan yang tepat untuk kondisi jalan tersebut pada Ruas Mako-Modanmohe Provinsi Maluku.

\section{TINJAUAN PUSTAKA}

\section{Sistem Penilaian Kondisi Permukaan Menurut Bina Marga}

Dalam buku manual konstruksi dan bangunan yang membahas tentang survei kondisi jalan untuk pemeliharaan rutin no 001-01/ M/BM/2011 dimana meliputi ketentuan umum dan teknis, dalam ketentuan umum yang memuat persyaratan, serta ketentuan teknis yang berisi metode survei kondisi jalan (Direktorat Jenderal Bina Marga, 2011). Pengkajian kondisi permukaan jalan dengan pengamatan langsung di lapangan dan diidentifikasi sesuai tingkat kerusakan dalam penelitian ini menggunakan kombinasi International Roughnes Index (IRI) dan Surface Distress Index (SDI). Pada Gambar 1 dapat dilihat bagaimana cara mengetahui kondisi jalan aspal.

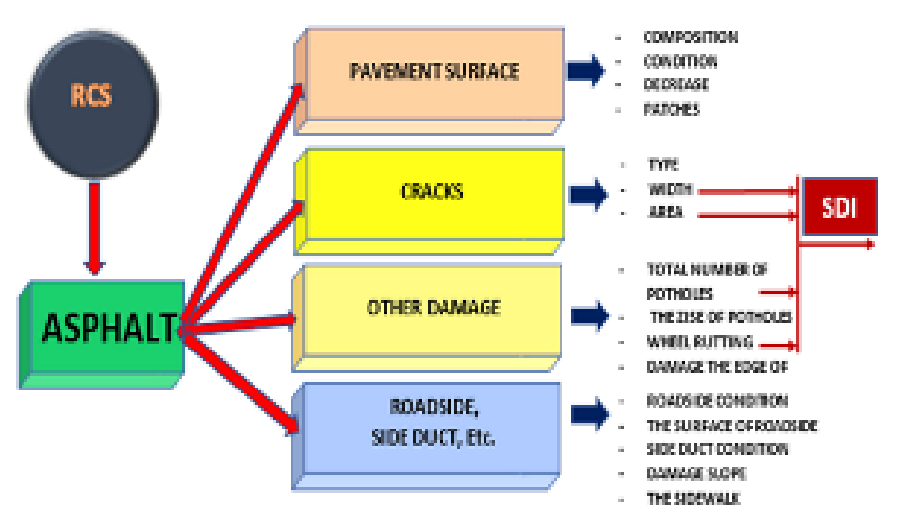

Sumber: (Direktorat Jenderal Bina Mar, 2011)

Gambar 1. Tinjauan jalan aspal

\section{Perhitungan Surface Distress Index (SDI)}

Ada 4 unsur penilaian yang diperlukan dalam perhitungan SDI yaitu : \% luas retak, rata-rata lebar retak, jumlah lubang $/ \mathrm{km}$ dan rata-rata kedalaman bekas roda/rutting. Dari keempat unsur diatas dilakukan berdasarkan RCS.

Tabel 1. Penilaian luas retak

\begin{tabular}{ccc}
\hline No & $\begin{array}{c}\text { Kategori Luas Retak } \\
\mathbf{( \% )}\end{array}$ & Nilai SDI* \\
\hline 1 & Tidak ada & - \\
2 & $<10$ & 5 \\
3 & $10-30$ & 20 \\
4 & $>30$ & 40 \\
\hline Sumber: (Direktorat Jenderal Bina Mar 2011$)$
\end{tabular}

Sumber: (Direktorat Jenderal Bina Mar, 2011) 
Tabel 1 merupakan tabel penilaian luas retak, dimana luasan retak dihitung dalam persen terhadap luas jalan dalam interval $100 \mathrm{~m}$. Misalnya luasan retak $<10 \%$ maka nilai SDIa adalah 5.

Tabel 2. Penilaian lebar retak

\begin{tabular}{ccc}
\hline No & Kategori Lebar Retak & Nilai SDI* \\
\hline 1 & Tidak ada & - \\
2 & Halus $<1 \mathrm{~mm}$ & - \\
3 & Sedang $1-3 \mathrm{~mm}$ & - \\
4 & Lebar $>3 \mathrm{~mm}$ & Nilai SDI* $\mathrm{x} 2$ \\
\hline Sumber: (Direktorat Jenderal Bina Mar, 2011)
\end{tabular}

Pada tabel 2 yang dinilai adalah lebar retak masing-masing kerusakan. Ini lebih ditekankan pada kerusakan retak rambut, retak buaya dan retak pinggir. Misalnya lebar retakan $>3 \mathrm{~mm}$ maka nilai SDI adalah nilai SDIax2.

Tabel 3. Penilaian jumlah lubang

\begin{tabular}{ccc}
\hline No & Kategori Jumlah Lubang & Nilai SDIc $^{c}$ \\
\hline 1 & Tidak ada & - \\
2 & $<10 / 100 \mathrm{~m}$ & Nilai SDI $^{\mathrm{b}}+15$ \\
3 & $10-50 / 100 \mathrm{~m}$ & Nilai SDI $^{\mathrm{b}}+75$ \\
4 & $>50 / 100 \mathrm{~m}$ & Nilai SDI $^{\mathrm{b}}+225$ \\
\hline
\end{tabular}

Sumber: (Direktorat Jenderal Bina Mar, 2011)

Tabel 3 merupakan tabel penilaian jumlah lubang, dimana jumlah lubang dihitung pada interval $100 \mathrm{~m}$. Misalnya jumlah lubang dalam $100 \mathrm{~m}$ adalah 20 maka nilai SDIc adalah nilai SDI ${ }^{\mathrm{b}}+75$.

Tabel 4. Penilaian bekas roda

\begin{tabular}{ccc}
\hline No & Kategori Jumlah Lubang & Nilai SDIc $^{\mathbf{c}}$ \\
\hline 1 & Tidak ada & - \\
2 & $<1 \mathrm{~cm}$ dalam & Nilai SDI $+5 \times 0.5$ \\
3 & $1-3 \mathrm{~cm}$ dalam & Nilai SDI $+5 \times 2$ \\
4 & $>3 \mathrm{~cm}$ dalam & Nilai SDI $+5 \times 4$ \\
\hline
\end{tabular}

Sumber: (Direktorat Jenderal Bina Mar, 2011)

Pada tabel 4 yang dinilai adalah penilaian bekas roda. Ini lebih ditekankan pada kedalaman kerusakan akibat bekas roda kendaraan. Misalnya lebar retakan $>3 \mathrm{~cm}$ maka nilai SDI adalah nilai SDI $+5 x 4$.

Dari tabel penilaian diatas dapat dilihat secara singkat pada diagram alir dan perhitungan Surface Distress Index (SDI) yang terdapat pada gambar 2 dan gambar 3.

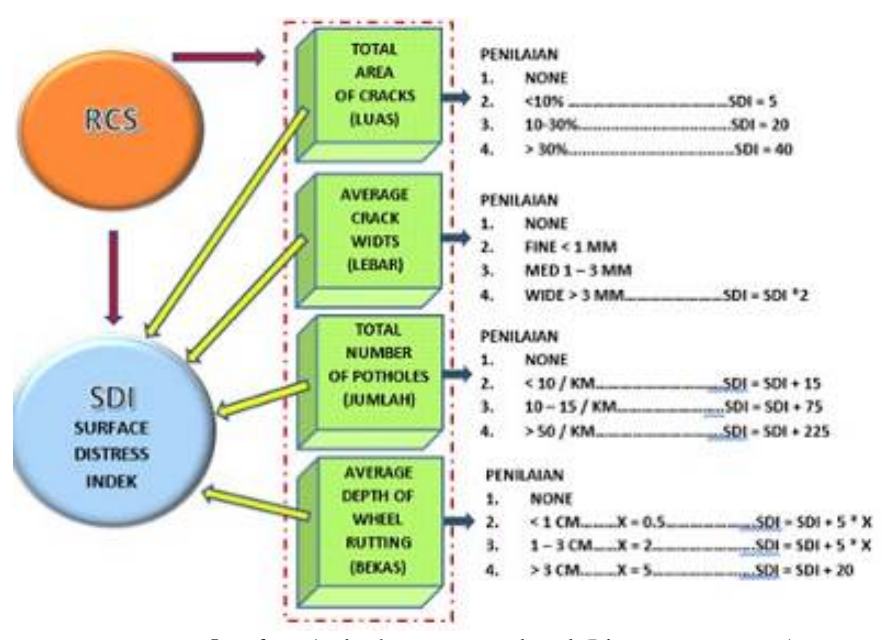

Sumber: (Direktorat Jenderal Bina Mar, 2011)

Gambar 2. Diagram Alir perhitungan Surface Distress Index (SDI) 


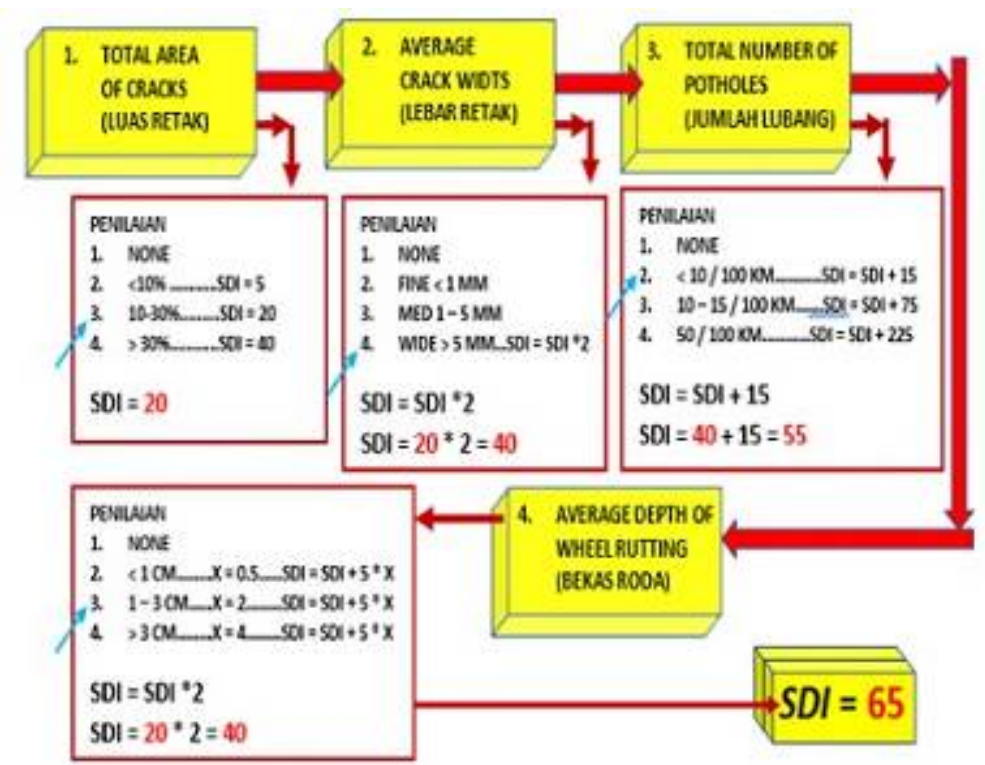

Sumber: (Direktorat Jenderal Bina Mar, 2011)

Gambar 3. Contoh perhitungan Surface Distress Index (SDI)

Pengelompokan kondisi jalan berdasarkan nilai SDI dapat dilihat pada tabel 5.

Tabel 5. Hubungan kondisi Jalan dengan nilai SDI

\begin{tabular}{lll}
\hline No & Kondisi Jalan & Nilai SDI \\
\hline 1 & Baik & $<50$ \\
2 & Sedang & $50-100$ \\
3 & Rusak Ringan & $100-150$ \\
4 & Rusak Berat & $>100$ \\
\hline
\end{tabular}

Sumber: (Direktorat Jenderal Bina Mar, 2011)

Pengelompokkan kondisi jalan berdasarkan nilai SDI dan data IRI dapat dilihat pada tabel 6.

Tabel 6. Penentuan kondisi segmen jalan

\begin{tabular}{ccccc}
\hline \multirow{2}{*}{ IRI } & \multicolumn{4}{c}{ SDI } \\
\cline { 2 - 5 } & $<50$ & $50-100$ & $100-150$ & 150 \\
\hline$<4$ & Baik & Sedang & Sedang & Rusak Ringan \\
$4-8$ & Sedang & Sedang & Rusak Ringan & Rusak Ringan \\
$8-12$ & Rusak Ringan & Rusak Ringan & Rusak Berat & Rusak Berat \\
$>12$ & Rusak Berat & Rusak Berat & Rusak Berat & Rusak Berat \\
\hline
\end{tabular}

Sumber: (Direktorat Jenderal Bina Mar, 2011)

Hasil dari penilaian kondisi kerusakan jalan berdasarkan Pedoman Konstruksi dan Bangunan No. 00104/P/BM/2011, Survei Kondisi Jalan, DJBM PU adalah penentuan jenis penanganan jalan dapat dilihat pada tabel 7 (Direktorat Jenderal Bina Mar, 2011).

Tabel 7. Penentuan jenis penanganan jalan

\begin{tabular}{ccccc}
\hline \multirow{2}{*}{ IRI } & \multicolumn{3}{c}{ SDI } & 150 \\
\cline { 2 - 5 } & $<50$ & $50-100$ & $100-150$ & Rekonstruksi \\
44 & Rutin & Rutin & Rehabilitasi & Rekonstruksi \\
$4-8$ & Rutin & Rutin & Rehabilitasi & Rekonstrin \\
$8-12$ & Rehabilitasi & Rehabilitasi & Rekonstruksi & Rekonstruksi \\
$>12$ & Rekonstruksi & Rekonstruksi & Rekonstruksi & Rekonstruksi \\
\hline
\end{tabular}

Sumber: (Direktorat Jenderal Bina Mar, 2011) 


\section{METODOLOGI PENELITIAN}

Data primer dalam penelitian ini diperoleh dari survei kondisi jalan pada ruas Jalan Nasional Mako-Modanmohe Pulau Buru Provinsi Maluku dimulai dari Km 38+100 sampai dengan Km 40+200. Penelitian ini dilaksanakan dengan melakukan survei langsung secara visual dilapangan dan mengklasifikasikan kerusakan berdasarkan tingkat kerusakannya. Sedangkan data sekunder dalam penelitian ini diperoleh dari Pejabat Pembuat Komitmen (PPK) wilayah 1.2 (Pulau Buru). Langkah selanjutnya dilakukan evaluasi tingkat kerusakan jalan dengan system penilaian kondisi perkerasan Bina Marga. Tahapan penelitian disajikan pada gambar 4.

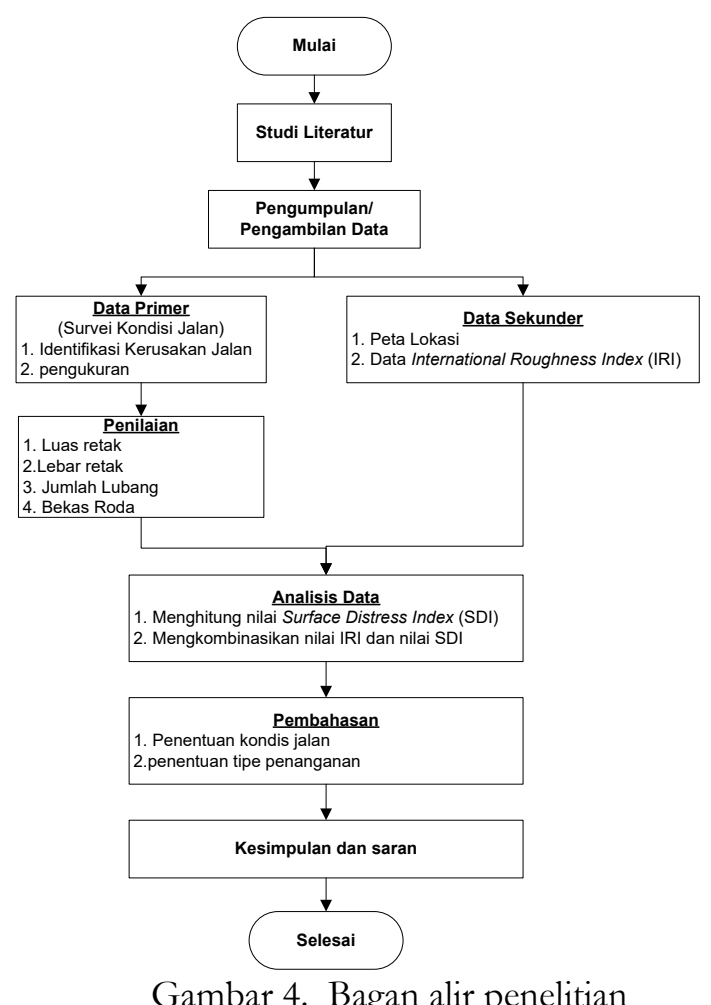

\section{ANALISIS DAN PEMBAHASAN}

Penilaian Kondisi Jalan

Bentuk tipikal jalan pada segmen ruas Jalan Mako-Modanmohe dapat disajikan pada tabel 8.

Tabel 8. Bentuk Tipikal Jalan lokasi penelitian

\begin{tabular}{llll}
\hline \multicolumn{2}{c}{ Lokasi (STA) } & Panjang Jalan (m) & Lebar Jalan (m) \\
\hline $38+100$ & $38+200$ & 100 & 4.5 \\
$38+200$ & $38+300$ & 100 & 4.5 \\
$38+300$ & $38+400$ & 100 & 4.5 \\
$38+400$ & $38+500$ & 100 & 4.5 \\
$38+500$ & $38+600$ & 100 & 4.5 \\
$38+600$ & $38+700$ & 100 & 4.5 \\
$38+700$ & $38+800$ & 100 & 4.5 \\
$38+800$ & $38+900$ & 100 & 4.5 \\
$38+900$ & $39+000$ & 100 & 4.5 \\
$39+000$ & $39+100$ & 100 & 4.5 \\
$39+100$ & $39+200$ & 100 & 4.5 \\
$39+200$ & $39+300$ & 100 & 4.5 \\
$39+300$ & $39+400$ & 100 & 4.5 \\
$39+400$ & $39+500$ & 100 & 4.5 \\
$39+500$ & $39+600$ & 100 & 4.5 \\
$39+600$ & $39+700$ & 100 & 4.5 \\
$39+700$ & $39+800$ & 100 & 4.5 \\
\hline
\end{tabular}




\begin{tabular}{llll}
\hline $\begin{array}{l}\text { Lokasi } \\
\text { (STA) }\end{array}$ & $\begin{array}{l}\text { Panjang } \\
\text { Jalan }(\mathbf{m})\end{array}$ & Lebar Jalan (m) & Lokasi (STA) \\
\hline $39+800$ & $39+900$ & 100 & 4.5 \\
$39+900$ & $40+000$ & 100 & 4.5 \\
$40+000$ & $40+100$ & 100 & 4.5 \\
$40+100$ & $40+200$ & 100 & 4.5 \\
\hline
\end{tabular}

Penentuan kondisi jalan ditentukan dari hasil kombinasi nilai IRI dan penilaian SDI. Hasil yang diperoleh dari kombinasi tersebut dapat menentukan kondisi jalan yaitu kondisi baik, kondisi sedang, kondisi rusak ringan maupun kondisi rusak berat pada jarak interval per 100 meter.

Tabel 9. Penentuan jenis penanganan jalan

\begin{tabular}{clllll}
\hline \multicolumn{2}{c}{ Lokasi (STA) } & Nilai IRI & Nilai SDI & $\begin{array}{l}\text { Kondisi Segmen Jalan } \\
\text { (SDI dan IRI) }\end{array}$ & $\begin{array}{l}\text { Jenis Penanganan } \\
\text { (SDI dan IRI) }\end{array}$ \\
\hline $38+100$ & $38+200$ & 5.22 & 40 & Sedang & Rutin \\
$38+200$ & $38+300$ & 6.89 & 0 & Sedang & Rutin \\
$38+300$ & $38+400$ & 5.71 & 0 & Sedang & Rutin \\
$38+400$ & $38+500$ & 4.27 & 0 & Sedang & Rutin \\
$38+500$ & $38+600$ & 4.64 & 55 & Sedang & Rutin \\
$38+600$ & $38+700$ & 4.21 & 0 & Rutin \\
$38+700$ & $38+800$ & 4.89 & 120 & Rusak Ringan & Rehabilitasi \\
$38+800$ & $38+900$ & 3.5 & 60 & Sedang & Rutin \\
$38+900$ & $39+000$ & 4.32 & 60 & Sedang & Rutin \\
$39+000$ & $39+100$ & 5.22 & 55 & Sedang & Rutin \\
$39+100$ & $39+200$ & 3.83 & 0 & Baik & Rutin \\
$39+200$ & $39+300$ & 3.81 & 0 & Baik & Rutin \\
$39+300$ & $39+400$ & 3.55 & 0 & Baik & Rutin \\
$39+400$ & $39+500$ & 3.59 & 0 & Baik & Rutin \\
$39+500$ & $39+600$ & 3.51 & 0 & Baik & Rutin \\
$39+600$ & $39+700$ & 4.63 & 5 & Sedang & Rutin \\
$39+700$ & $39+800$ & 4.64 & 0 & Sedang & Rutin \\
$39+800$ & $39+900$ & 4.9 & 0 & Sedang & Rutin \\
$39+900$ & $40+000$ & 4.92 & 0 & Sedang & Rutin \\
$40+000$ & $40+100$ & 5.1 & 0 & Sedang & Sedang \\
$40+100$ & $40+200$ & 4.62 & 60 & & Rutin \\
\hline
\end{tabular}

Dari hasil evaluasi jalan yang diperoleh pada segmen Ruas Jalan Mako-Modanmohe dapat ditentukan kondisi jalan yang disajikan pada tabel 10 dan gambar 5 .

Tabel 10. Persentase kondisi jalan

\begin{tabular}{ll}
\hline Kondisi Jalan & $\mathbf{( \% )}$ \\
\hline Baik & 23.81 \\
Sedang & 71.43 \\
Rusak Ringan & 4.76 \\
Rusak Berat & 0 \\
\hline
\end{tabular}




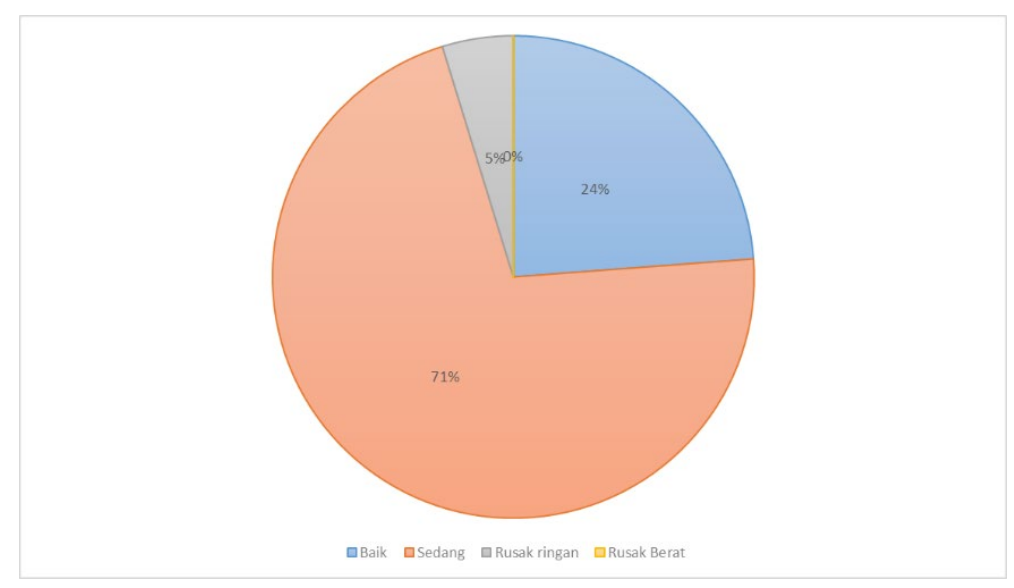

Gambar 5. Persentase kondisi jalan

Berdasarkan hasil evaluasi jalan yang diperoleh pada segmen ruas Jalan Mako-Modanmohe dapat ditentukan jenis penaganan yang terdapat pada tabel 11 dan gambar 6 .

Tabel 11. Persentase penanganan jalan

\begin{tabular}{ll}
\hline Kondisi Jalan & $\mathbf{( \% )}$ \\
\hline Rutin & 95.24 \\
Rehabilitasi & 4.76 \\
Rekostruksi & 0 \\
\hline
\end{tabular}

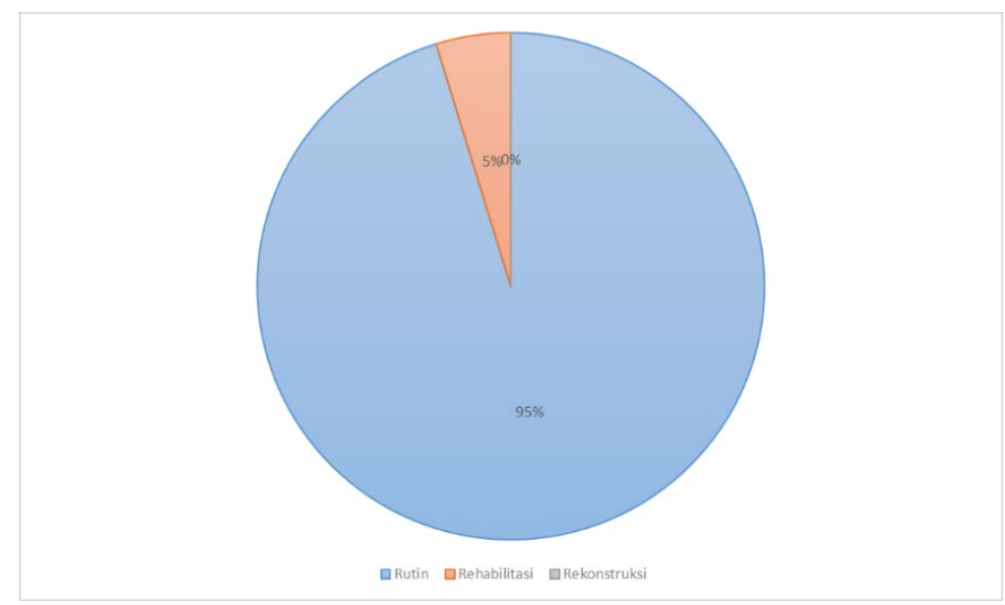

Gambar 6. Persentase penanganan jalan

\section{SIMPULAN}

Berdasarkan hasil penelitian diperoleh kesimpulan sebagai berikut:

1. Jenis dan tingkat kerusakan permukaan jalan pada segmen ruas Mako-Modanmohe Km $38+100-\mathrm{km}$ $40+200$ adalah baik $23.81 \%$, sedang $71.43 \%$, rusak ringan $4.76 \%$ dan rekonstruksi $0 \%$.

2. Jenis penanganan dalam segmen jalan ruas Mako-Modanmohe adalah rutin $95.24 \%$, rehabilitasi $4.76 \%$ dan rekonstruksi $0 \%$.

\section{REFERENSI}

Aptarila, G.,2020, "Analisis Kerusakan Jalan Metode SDI Taluk Kuantan - Batas Provinsi Sumatera Barat", SIKLUs Jurnal Tek. Sipil, Vol. 6 No.2, pp. 195-203.

Baihaqi: Salaeh, M. A., 2018, "Tinjauan Kondisi Perkerasan Jalan dengan Kombinasi nilai International Roughness Index (IRI) dan Surface Distress Index (SDI) pada Jalan Takengon - Blankejeren", Journal Tek. Sipil Univ. Syiah Kuala, Vol. 1 No. 3, pp. 543-552. 
Bunga, D. M., 2019, "Effect of Collision Variation towards the Index Retained Strength of Mixed Asphalt Concrete Wearing Course", Int. J. Sci. Eng. Sci,Vol. 3 No. 8, pp. 61-64.

Direktorat Jenderal Bina Mar., 2011, "Pedoman Konstruksi dan Bangunan. No. 00104/P/BM/2011, Survei Kondisi Jalan", Kementerian Pekerjaan Umum. Jakarta.

Direktorat Jenderal Bina Marga., 2011, "Manual Konstruksi dan Bangunan. No. 001-01/M/BM/2011, Survei Kondisi Jalan untuk Pemeliharaan Rutin", Kementerian Pekerjaan Umum. Jakarta

Futwenbun, R. S., 2017, "Evaluasi Tingkat Kerusakan Jalan Sebagai Dasar Penanganan Jalan (Studi Kasus Pada Ruas Jalan Sp Taniwel - Boeria)", J. MANUMATA. Vol. 3 No. 2, pp. 63-70.

Kamba, C. R., 2018, "Marshall Characteristics Test on hot Rolled Sheet Base Combine Using Nickel slag For Half Gap Graded", Int. Joumal. Innov. Sci. Eng. Techno.Vol. 5 No. 3, pp. 14-19.

Pembuain.A., Priyanto, S. S., 2018, "Evaluasi Kemantapan Permukaan Jalan Berdasarkan International Roughness Index Pada 14 Ruas Jalan di Kota Yogyakarta", TEKNIK, Vol. 39 No. 2, pp. 126-131.

Sukirman, S., 2007, "Beton Aspal Campuran Panas", Yayasan Obor Indonesia. Jakarta.

Tho'atin, U. S., 2016, "Penggunaan Metode International Roughness Index (IRI), Surface Distress Index (SDI) dan Pavement Condition Index (PCI) untuk Penilaian Kondisi Jalan di Kabupaten Wonogiri", Seminar Nasional Sains dan Teknologi, pp. 1-9. 